\title{
Expression of Shelterin Component POT1 Is Associated with Decreased Telomere Length and Immunity Condition in Humans with Severe Aplastic Anemia
}

\author{
Ting Wang, Shu-chong Mei, Rong Fu, Hua-quan Wang, and Zong-hong Shao \\ Department of Hematology, General Hospital, Tianjin Medical University, 154 Anshandao, Heping, Tianjin 300052, China \\ Correspondence should be addressed to Zong-hong Shao; shaozonghong@sina.com
}

Received 24 February 2014; Revised 14 April 2014; Accepted 16 April 2014; Published 6 May 2014

Academic Editor: Xiao-Feng Yang

Copyright (c) 2014 Ting Wang et al. This is an open access article distributed under the Creative Commons Attribution License, which permits unrestricted use, distribution, and reproduction in any medium, provided the original work is properly cited.

\begin{abstract}
Abnormal telomere attrition has been found to be closely related to patients with SAA in recent years. To identify the incidence of telomere attrition in SAA patients and investigate the relationship of telomere length with clinical parameters, SAA patients $(n=27)$ and healthy controls $(n=15)$ were enrolled in this study. Telomere length of PWBCs was significantly shorter in SAA patients than in controls. Analysis of gene expression of Shelterin complex revealed markedly low levels of POT1 expression in SAA groups relative to controls. No differences in the gene expression of the other Shelterin components-TRF1, TRF2, TIN2, TPP1, and $R A P 1$-were identified. Addition of IFN- $\gamma$ to culture media induced a similar fall in POT1 expression in bone marrow cells to that observed in cells cultured in the presence of SAA serum, suggesting IFN- $\gamma$ is the agent responsible for this effect of SAA serum. Furthermore, ATR, phosphorylated ATR, and phosphorylated ATM/ATR substrate were all found similarly increased in bone marrow cells exposed to SAA serum, TNF- $\alpha$, or IFN- $\gamma$. In summary, SAA patients have short telomeres and decreased POT1 expression. TNF- $\alpha$ and IFN- $\gamma$ are found at high concentrations in SAA patients and may be the effectors that trigger apoptosis through POT1 and ATR.
\end{abstract}

\section{Introduction}

Telomeres are located at the end of linear eukaryotic chromosomes and consist of repetitive TTAGGG DNA sequences and specific interacting proteins that together form a capping structure that prevents chromosomal damage and degradation [1]. A small amount of telomere length is normally lost during each cell division, with telomere homeostasis being a complex process affected by both intrinsic and extrinsic factors. These include heredity, epigenetics, and environmental factors such as inflammation and stress [2]. Telomere length can be influenced directly by the telomerase enzyme and indirectly by a group of proteins known as the Shelterin complex.

Aplastic anemia (AA) is a potentially life-threatening failure of hemopoiesis characterized by pancytopenia and hypocellular bone marrow. Other than those patients with inherited conditions, most cases are acquired and immunemediated [3]. Shortened telomeres were first identified in
AA patients more than a decade ago [4], with about onethird to one-half of AA patients possessing short telomeres. Those with the shortest telomeres appear to have had longer disease duration and were more likely to develop latent malignant clonal changes. Several studies have identified telomere length improvement with disease recovery, while patients with irreversible telomere attrition typically have poor outcomes $[5,6]$. Our department treats many patients with severe aplastic anemia (SAA). In this study, our first aim was to identify the incidence of telomere shortening in SAA patients and to ascertain whether telomere length correlates with clinical parameters.

Previous studies have determined that most family members of AA patients with short telomeres have deficiencies in bone marrow hematopoietic function. AA with telomere attrition has therefore been recognized as a genomic disease and stem cell transplant is currently the only effective treatment available. Many AA patients with short telomeres carry mutations in genes such as those encoding the telomerase 
components TERT or TERC, the genes NOP10 and NOLA1, and the genes of Shelterin components [7-9]. However, the rate of mutations within these genes is insufficient to explain the high incidence of shortened telomeres in AA. It has been reported that the proportion of AA cases with TERC and TERT mutations is about 5-10 percent, with mutations in other genes such as those of Shelterin components rare and predominantly found in pediatric cases [10]. Therefore, in addition to genetic mutations, we speculate that other mechanisms lead to telomere attrition in AA. In this study we focus on the Shelterin complex and POT1 in particular.

The Shelterin complex interacts directly with telomeric DNA and mediates telomere homeostasis by allowing access to both positive and negative regulators of telomere length that use both telomerase-dependent and telomeraseindependent mechanisms [11]. In this study, we further investigate expression of Shelterin complex components at different stages of SAA progression from newly detected disease to posttreatment and probe for clues as to how telomere attrition and Shelterin abnormalities could trigger SAA.

\section{Materials and Methods}

2.1. Patients and Controls. Peripheral blood and bone marrow samples from SAA patients and age matched controls were obtained after written informed consent had been received in accordance with the Declaration of Helsinki. SAA diagnosis was established by bone marrow biopsy, bone marrow smear, and peripheral blood cell count. SAA was defined by the following criteria: (1) bone marrow cellularity $<25 \%$ or $25-$ $50 \%$ with $<30 \%$ residual (hematopoietic) cells; (2) two of the following three: neutrophils $<0.5 \times 10^{9} / \mathrm{L}$, platelets $<20$ $\times 10^{9} / \mathrm{L}$, and reticulocytes $<20 \times 10^{9} / \mathrm{L}$; (3) no malignant cell infiltration, no extensive marrow fibrosis, no extensive iron deposition, no evidence of malignant disease, and no myelofibrosis, storage disease, or chemotherapy.

Recovering SAA patients were those who improved after therapy with antithymocyte globulin, cyclosporine, glucocorticoid, and hematopoietic stimulating factors (recombinant human erythropoietin, granulocyte colony-stimulating factor, recombinant human thrombopoietin, and/or IL-11 in combination). All recovering patients achieved bone marrow hematopoietic recovery, which was defined as substantial improvement in 2-3 lineages. Some patients became transfusion independent while some had normal peripheral blood cell counts but still required drug therapy.

2.2. Measurement of Telomere Length. DNA was extracted from $1-2 \times 10^{6}$ target cells by a DNA extraction kit (Tian'enze Biotech, Beijing, China). Mean length of terminal restriction fragments (TRF) was measured using the TeloTAGGG telomere length assay kit (Roche). Purified DNA (1-2 $\mu$ g) was digested with HinfI/RsaI mixture. Following electrophoresis and transfer, the membrane containing DNA was hybridized to digoxigenin-labeled probe specific for telomeric DNA repeats. After incubation with a digoxigenin-specific antibody, TRF length was visualized by a highly sensitive chemiluminescent reagent in the kit by gel imaging analysis system (Genesnap G, Gene Company, American). Overall mean TRF length was determined using Gene Tools software.

2.3. RNA Isolation and $q P C R$. PBMCs were lysed $(1-2 \times$ $10^{6}$ target cells) in TRIzol reagent (Invitrogen, USA). Total RNA was isolated according to the manufacturer's protocol (Invitrogen). Total RNA was dissolved in RNase-free water and quantified using a UV spectrophotometer (NanoDrop ND-1000, Thermo Scientific, USA). Equal amounts of RNA were reverse transcribed using the High-Capacity Reverse Transcription kit (TianGen Biotech, China) according to manufacturer's protocol. Real-time PCR was performed with $2 \mu \mathrm{L}$ of each cDNA working solution in a final volume of $20 \mu \mathrm{L}$ containing $10 \mu \mathrm{L} 2 \mathrm{x}$ RealMasterMix/20x SYBR solution (TianGen Biotech) and $300 \mathrm{nM}$ of each sense and antisense primer. PCR was carried out in a Bio-Rad PCR iQ5 (BioRad, USA) using the following thermal cycling profile for all genes of interest: $95^{\circ} \mathrm{C}$ for $15 \mathrm{~min}$, followed by 40 cycles of amplification $\left(95^{\circ} \mathrm{C}\right.$ for $10 \mathrm{~s}$, indicated annealing temperature for $30 \mathrm{~s}, 72^{\circ} \mathrm{C}$ for $32 \mathrm{~s}$, and $55^{\circ} \mathrm{C}$ for $10 \mathrm{~s}$ ). Absorption values of the SYBR Green I in each tube were detected at the end of each cycle. A melting curve analysis of PCR products from 55 to $95^{\circ} \mathrm{C}$ was also performed after PCR amplification. Primer sequences and annealing temperature are listed in Table 1 . The relative expression level of genes of interest was calculated by the $\Delta \Delta C_{t}$ method (User Bulletin number 2, ABI PRISM 7700 Sequence Detection System).

2.4. Cell Culture. $3 \times 10^{6}$ of target bone marrow mononuclear cells (BMMNCs) were maintained in four different cell culture conditions: Group 1: RPMI1640 (Invitrogen, USA) supplemented with $10 \%$ fetal bovine serum (FBS, HYCLONE, USA); Group 2: 1640 medium supplemented with 10\% SAA serum; Group 3: 1640 medium supplemented with 10\% FBS and 100U/mL TNF- $\alpha$; Group 4: 1640 medium supplemented with $10 \%$ FBS and $100 \mathrm{U} / \mathrm{mL}$ IFN- $\gamma$. The cultures were incubated at $37^{\circ} \mathrm{C}$ in humidified $95 \%$ air with $5 \% \mathrm{CO}_{2}$ for 24 hours

2.5. Flow Cytometry for Apoptosis Analysis. Apoptosis was detected using a commercially available Annexin V apoptosis detection kit (Becton Dickinson, USA) and flow cytometry. Following $24 \mathrm{~h}$ incubation under indicated culture conditions, cultured cells from groups 1 and 2 were harvested, washed with ice-cold phosphate-buffered saline (PBS), and incubated with HEPES buffer. Cells were washed with binding buffer and then analyzed with a FACSCalibur flow cytometer (Becton Dickinson). Approximately 20,000 counts were made for each sample.

2.6. Immunoblotting. Cultured cells were collected and lysed directly in lysis buffer supplemented with complete protease inhibitor cocktail (Roche, Switzerland) and phosphatase inhibitors (Roche, Switzerland). Protein levels were quantified using the BCA method. Proteins were subjected to 
TABLE 1: Target gene primer sequences and annealing temperature.

\begin{tabular}{|c|c|c|}
\hline Gene & Primer $\left(5^{\prime} \rightarrow 3^{\prime}\right)$ & Annealing temperature $\left({ }^{\circ} \mathrm{C}\right)$ \\
\hline$\beta$-Actin & $\begin{array}{l}\text { F CCTCATGCCATCCTGCGTCTG } \\
\text { R TTGCTCGAAGTCTAGGGCAACATAG }\end{array}$ & 58 \\
\hline TRF1 & $\begin{array}{l}\text { F AAGTCCTGAAAGCCCTGAATC } \\
\text { R TTCCTGTGCCTCCAAAATCT }\end{array}$ & 58 \\
\hline TRF2 & $\begin{array}{l}\text { F CTGTATTCATTTTGCTAACTTAG } \\
\text { R ATTCTTAACACTCTCTAGAGTTG }\end{array}$ & 55 \\
\hline TIN2 & $\begin{array}{l}\text { F CTTCATTCCTACTAAACTACTTG } \\
\text { R ACTGTAGAGACAGTTCTAGACCT }\end{array}$ & 57 \\
\hline POT1 & $\begin{array}{l}\text { F CAGAAAAGTGTGGATATG } \\
\text { R AAGTAAAAGAAGTGTGGG }\end{array}$ & 55 \\
\hline TPP1 & $\begin{array}{l}\text { F GCGTGACGTCTCACATCG } \\
\text { R ATCGTGATGGTTCTGCCTTC }\end{array}$ & 55 \\
\hline RAP1 & $\begin{array}{l}\text { F TGTGGTGTGTGTGTGTGTGG } \\
\text { R CCCCACACACACCACACAC }\end{array}$ & 56 \\
\hline
\end{tabular}

TABLE 2: Clinical and demographic parameters of patients participating in the study.

\begin{tabular}{|c|c|c|c|c|c|c|c|c|}
\hline Diagnosis & Number & Age (y) & $\begin{array}{l}\text { Duration } \\
\text { (mo) }\end{array}$ & $\begin{array}{c}\text { ANC } \\
\left(/ \mathrm{mm}^{3}\right)\end{array}$ & $\begin{array}{c}\mathrm{Hb} \\
(\mathrm{g} / \mathrm{dL})\end{array}$ & $\begin{array}{c}\text { Plts } \\
\left(10^{3} / \mathrm{mm}^{3}\right)\end{array}$ & Ret $\%$ & Therapy \\
\hline Untreated SAA & 9 & $\begin{array}{c}33 \\
(5-69)\end{array}$ & $2(1-4)$ & $0.31 \pm 0.20$ & $82.11 \pm 20.01$ & $11.22 \pm 5.85$ & $0.45 \pm 0.39$ & $\begin{array}{l}\text { Not previously } \\
\text { treated except for } \\
\text { transfusions }\end{array}$ \\
\hline Recovering SAA & 18 & $\begin{array}{c}20 \\
(5-48)\end{array}$ & $24(6-120)$ & $3.33 \pm 1.22$ & $118.94 \pm 16.78$ & $89.35 \pm 43.08$ & $1.14 \pm 0.27$ & $\begin{array}{l}\text { Treated with } \\
\text { combination } \\
\text { indicated }\end{array}$ \\
\hline $\begin{array}{l}\text { Recovering group before } \\
\text { combination treatment } \\
\text { except transfusion }\end{array}$ & 18 & $\begin{array}{c}18 \\
(4-47)\end{array}$ & $\begin{array}{l}\text { Unable to be } \\
\text { determined for } \\
\text { some patients }\end{array}$ & $0.21 \pm 0.15$ & $72.12 \pm 23.58$ & $9.71 \pm 4.89$ & $0.25 \pm 0.20$ & $\begin{array}{l}\text { Not previously } \\
\text { treated except for } \\
\text { transfusions }\end{array}$ \\
\hline
\end{tabular}

Values are mean \pm SEM. Age and duration values are mid (min, max). ANC: absolute neutrophil count; Hb: hemoglobin; Plt: platelet; Ret: reticulocyte.

SDS-PAGE and transferred onto a nitrocellulose membrane. Membranes were blocked with confining liquid (TianGen Biotech) and then probed with primary antibody solution. Primary antibodies, ATR, Phospho-ATR Ser428, and Phospho-Ser/Thr ATM/ATR substrate (Cell Signaling Technology, USA), were diluted with PBS to a final concentration of $1: 10,000$.

Incubation with relevant secondary antibodies (Zhongshan Biotech, China) was performed in PBS and visualization was achieved using Super ECL Plus Detection Reagent.

2.7. Statistical Analysis. All statistical calculations were performed using SPSS Statistics 15.0. Between-group differences were investigated by analysis of covariance (ANCOVA). Spearman's rank correlation test was used to calculate the correlation between telomere length and clinical data. Nonparametric tests were used when data was nonnormal distribution. Pre- and postlab data were compared by paired $t$-test. Statistical significance was accepted if $P<0.05$.

\section{Results}

3.1. Clinical and Demographic Parameter of Patients Participating in the Study. Twenty-seven SAA patients (age range 569 years) and 15 normal controls (age range 5-67 years) were enrolled in the present study. Within the SAA cohort, there were nine untreated and 18 recovering patients. Sequential samples from the same patient were excluded from the analysis. Table 2 details patient information.

3.2. Telomere Attrition of PWBCs in SAA and the Relationship between Telomere Length and Clinical Parameters. Telomere length in peripheral white blood cells (PWBCs) was found to be significantly shorter in untreated SAA patients $(4.89 \pm$ $1.66 \mathrm{~kb})$ and recovering SAA patients $(7.04 \pm 1.47 \mathrm{~kb})$ than in control patients $(11.65 \pm 5.55 \mathrm{~kb}$, Figure 1$)$. No significant difference in telomere length was detected between untreated SAA and recovering SAA patients. As expected, telomere length in PWBCs of healthy controls declined progressively with age $(r=-0.748 ; P=0.013)$. However, telomere length in SAA patient PWBCs was age independent, with no statistically significant age-related trend found in either the SAA untreated group $(r=-0.086 ; P=0.77)$ or the recovering group $(r=-0.433 ; P=0.244)$. Table 4 details ages and telomere length of both patients and controls.

Unexpectedly, shortened telomere length correlated with low hemoglobin $(r=0.732 ; P<0.0001)$, platelet count $(r=$ $0.681 ; P=0.0004)$, absolute neutrophil count $(r=0.617$; $P=0.0017)$, and proportion of reticulocytes in peripheral blood $(r=0.633 ; P=0.001)$. Furthermore, the ratio of 
TABLE 3: Shelterin complex mRNA expression in PWBCs $\left[x \pm s, \mathrm{M}\left(P_{25}-P_{75}\right)\right]$.

\begin{tabular}{lcccc}
\hline Gene & $\begin{array}{c}\text { Untreated group } \\
(n=9)\end{array}$ & $\begin{array}{c}\text { Recovering group } \\
(n=17)\end{array}$ & $\begin{array}{c}\text { Control group } \\
(n=15)\end{array}$ & $P$ value \\
\hline POT1 & $0.29(0.09-0.58)$ & $0.78(0.22-2.69)$ & $1.88(0.93-3.81)$ \\
TRF1 & $0.54(0.31-0.67)$ & $0.93(0.35-0.99)$ & $1.00(0.38-1.05)$ \\
TRF2 & $1.98(1.21-2.89)$ & $1.40(0.82-1.79)$ & $2.10(1.02-3.11)$ & $0.0137^{*}$ \\
TIN2 & $3.24(2.64-3.93)$ & $2.13(0.81-2.68)$ & $2.23(0.51-3.92)$ & 0.251 \\
TPP1 & $1.90(0.96-2.24)$ & $0.73(0.40-3.23)$ & $0.70(0.70-0.78)$ & 0.172 \\
RAP1 & $3.68(1.93-4.14)$ & $1.89(0.61-2.37)$ & $3.86(0.87-4.18)$ & 0.220 \\
\hline
\end{tabular}

Asterisk means there are significantly differences between untreated group, recovering group, and controls.

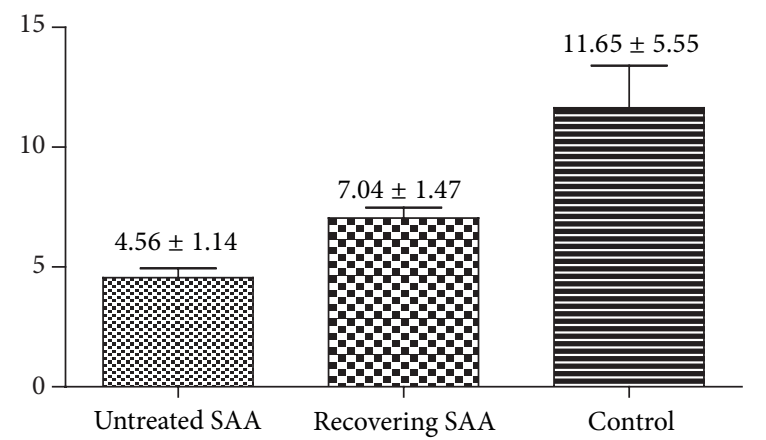

FIgURE 1: Telomere length of PWBCs.

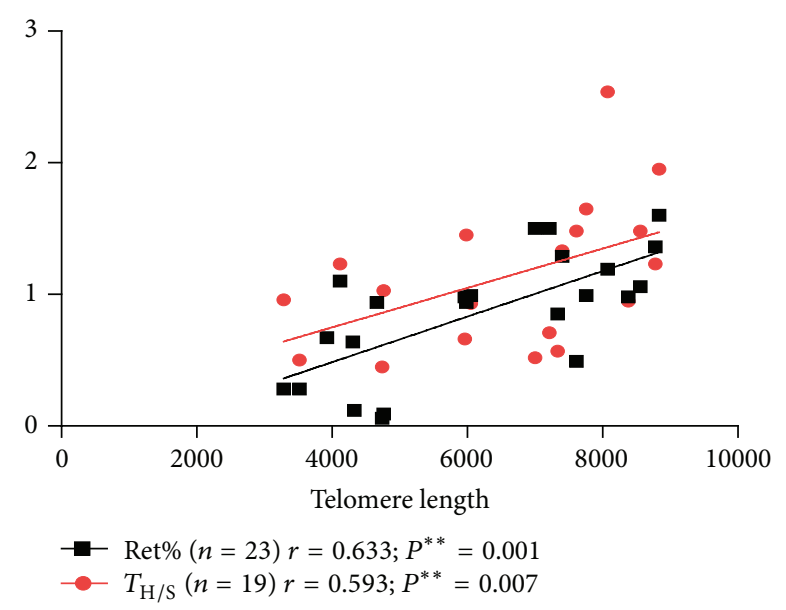

FIgURE 2: Relationship between TL and $\mathrm{T}_{\mathrm{H} / \mathrm{S}}$ and TL and Ret\%.

CD4+ T-helper lymphocytes to CD8+ T-suppressor $\left(\mathrm{T}_{\mathrm{H} / \mathrm{S}}\right)$ was found to correlate with the telomere length of PWBCs (both telomere length and $\mathrm{T}_{\mathrm{H} / \mathrm{S}}$ were measured in 19/27 patients; $r=0.593 ; P=0.007$; Figures 2 and 3 ). However, if untreated and recovering patients were divided into separate groups no relationship between the telomere length and the above clinical parameters was apparent.

There was no relationship between the telomere length of PWBCs in SAA patients and the absolute value of the lymphocyte count $(r=0.137 ; P=0.599)$; the recovery time of at least one lineage of bone marrow hematopoietic cells $(r=0.261 ; P=0.280)$; the recovery time of three
TABLE 4: Telomere length of SAA patients and controls.

\begin{tabular}{|c|c|c|c|}
\hline Number & Ages (y) & Group & TRF (kb) \\
\hline 1 & 69 & 1 & 7.61 \\
\hline 2 & 60 & 1 & 4.76 \\
\hline 3 & 16 & 1 & 4.33 \\
\hline 4 & 26 & 1 & 3.52 \\
\hline 5 & 44 & 1 & 3.54 \\
\hline 6 & 33 & 1 & 3.92 \\
\hline 7 & 49 & 1 & 4.74 \\
\hline 8 & 5 & 1 & 3.29 \\
\hline 9 & 20 & 1 & 6.30 \\
\hline 10 & 5 & 2 & 8.07 \\
\hline 11 & 18 & 2 & 4.66 \\
\hline 12 & 19 & 2 & 7.40 \\
\hline 13 & 20 & 2 & 7.21 \\
\hline 14 & 20 & 2 & 7.00 \\
\hline 15 & 23 & 2 & 6.05 \\
\hline 16 & 25 & 2 & 5.98 \\
\hline 17 & 27 & 2 & 5.98 \\
\hline 18 & 29 & 2 & 8.78 \\
\hline 19 & 31 & 2 & 4.31 \\
\hline 20 & 36 & 2 & 8.83 \\
\hline 21 & 45 & 2 & 8.38 \\
\hline 22 & 47 & 2 & 8.56 \\
\hline 23 & 48 & 2 & 5.96 \\
\hline 24 & 18 & 3 & 13.45 \\
\hline 25 & 67 & 3 & 7.40 \\
\hline 26 & 7 & 3 & 16.57 \\
\hline 27 & 35 & 3 & 10.41 \\
\hline 28 & 37 & 3 & 19.82 \\
\hline 29 & 25 & 3 & 9.20 \\
\hline 30 & 47 & 3 & 6.12 \\
\hline 31 & 48 & 3 & 7.08 \\
\hline 32 & 52 & 3 & 6.12 \\
\hline 33 & 15 & 3 & 20.34 \\
\hline
\end{tabular}

Group 1: untreated SAA patients $(n=9)$.

Group 2: recovering SAA patients $(n=14)$.

Group 3: controls $(n=10)$.

lineages of bone marrow hematopoietic cells $(r=0.253$; $P=0.363)$; the duration of disease $(r=0.193 ; P=0.378)$; the 


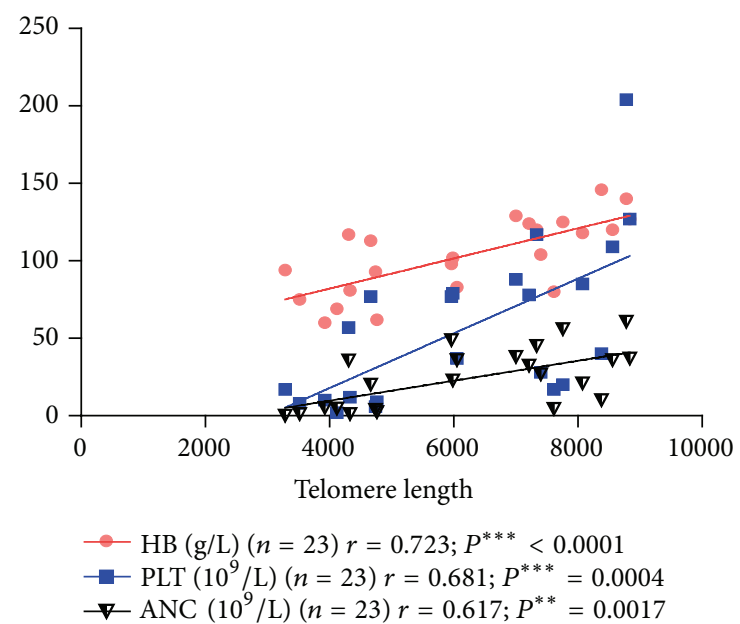

FIGURE 3: Relationship between hemoglobin, platelet count, absolute neutrophil count, and telomere length. HB: hemoglobin. PLT: platelet count. ANC: absolute neutrophil count.

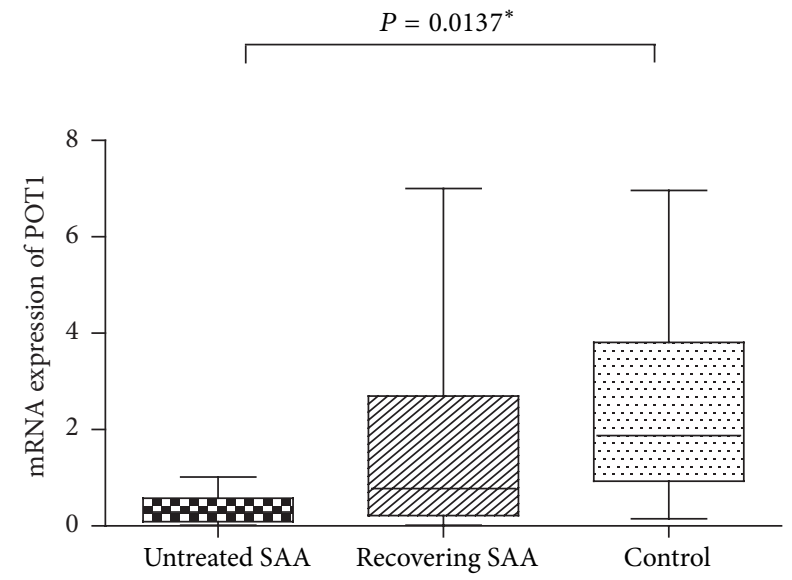

Figure 4: POT1 mRNA expression in different groups.

clone of paroxysmal nocturnal hemoglobinuria (PNH) cells $(r=-0.14, P=0.525)$; or the chromosomal abnormalities $(r=-0.257 ; P=0.236)$.

3.3. $m R N A$ Expression Abnormalities of Shelterin Complex Components in PWBCs from SAA Patients. Mammalian telomeres are associated with Shelterin, a protein complex that functions to protect DNA ends from being recognized as double strand breaks that would trigger a DNA damage response $[12,13]$. Proteins comprising the Shelterin complex are TRF1, TRF2, TIN2, RAP1, TPP1, and POT1. While each protein has been reported to participate in telomere synthesis and telomere protection, little is known about any potential role for them in AA. We measured the levels of mRNA of these genes in our patient samples and identified significantly lower expression of POT1 in the SAA untreated group (0.29, range: $0.09-0.58)$ relative to the recovering group $(0.78$, range: $0.22-2.69)$ and the control group (1.88, range: $0.93-$ 3.81; $P=0.0137$; Figure 4). No significant differences in the

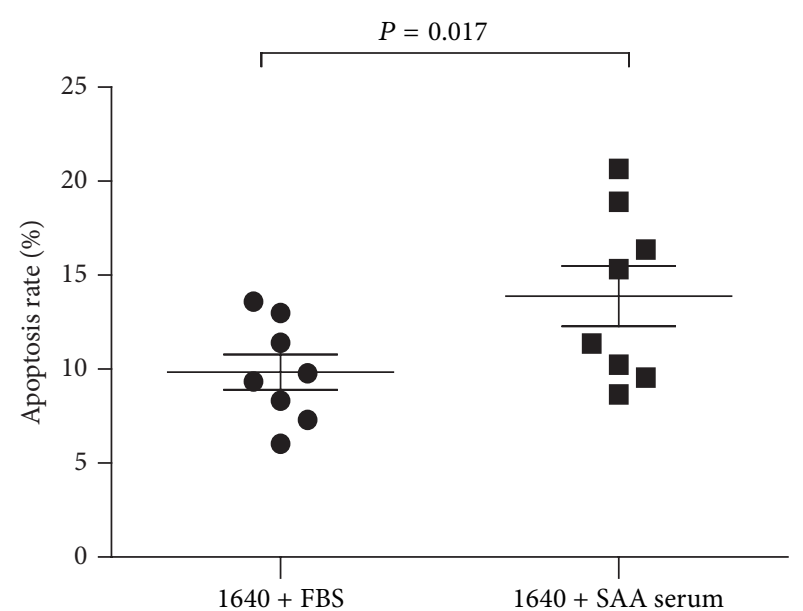

FIGURE 5: Normal BMMNCs cultured with SAA serum undergo a higher apoptosis rate than those cultured with FBS.

expression level of TRF1, TRF2, TIN2, TPP1, or RAP1 between groups were detected (Table 3 ).

Though low expression of POT1 was significantly associated with short telomeres $\left(r=0.398 ; P=0.022^{*}\right)$, there was no significant relationship between POT1 expression and $\mathrm{T}_{\mathrm{H} / \mathrm{S}}(r=0.168 ; P=0.467)$.

3.4. High Apoptosis Rate and Expression of ATM/ATR Proteins in SAA Serum Cultured Normal BMMNCs. High levels of apoptosis of hematopoietic cells in SAA patients have been previously reported, with high levels of TNF- $\alpha$ and IFN$\gamma$ suspected to contribute to this phenomenon [14]. Our research team has also detected high levels of these cytokines in SAA patient serum in the past. TNF- $\alpha$ and IFN- $\gamma$ reduce the numbers of human hematopoietic progenitor-derived colonies in vitro and efficiently induce apoptosis in CD34 target cells, at least partially through the Fas-dependent cell death pathway [15]. We cultured BMMNCs from eight normal control group patients and compared rates of apoptosis when these cells were cultured in media containing SAA serum or FBS. As expected, cells cultured with SAA serum underwent significantly higher levels of apoptosis (13.88 \pm 4.55) than those with FBS (9.85 $\pm 2.67 ; P=0.017$; Figure 5).

We next examined whether TNF- $\alpha$ or IFN- $\gamma$ was responsible for the decreased mRNA expression of POT1 identified in SAA patients. We chose eight normal control and eight untreated patients at random, isolated their BMMNCs, and cultured these normal BMMNCs in media containing SAA serum. POT1 mRNA expression in normal BMMNCs cultured with FBS was markedly higher $(1.17 \pm 0.57)$ than that in cells from SAA patients $(0.45 \pm 0.27$; these cells were harvested directly and not subjected to culture conditions), normal BMMNCs cultured with SAA serum $(0.49 \pm 0.38)$, and those cultured with $100 \mathrm{U} / \mathrm{mL}$ IFN- $\gamma(0.40 \pm 0.35$; Figure 6). Data for cells cultured in the presence of $100 \mathrm{U} / \mathrm{mL}$ TNF- $\alpha$ has been omitted as the majority (5/8) had zero POT1 expression. Taken together, these data suggest that a constituent of SAA serum-maybe TNF- $\alpha$, IFN- $\gamma$, or others-effectively reduced 


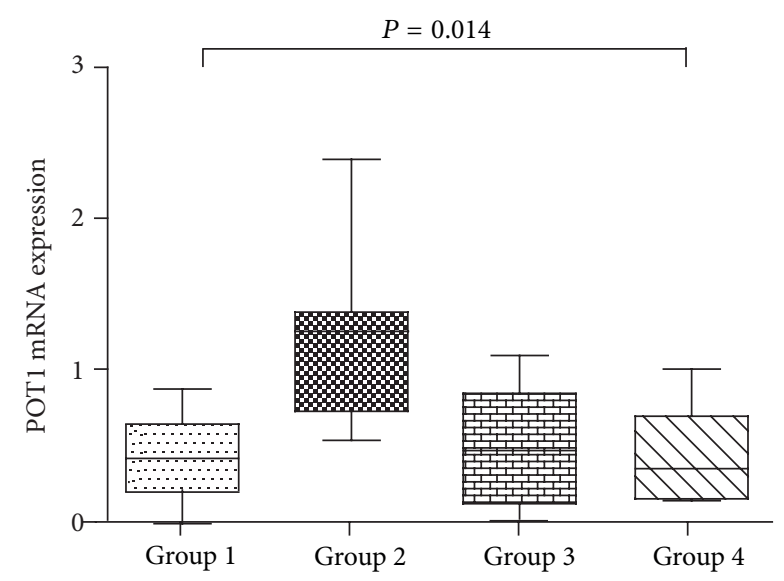

Group 1: SAA patient BMMNCs

Group 2: normal BMMNCs + FBS

Group 3: normal BMMNCs + SAA serum

Group 4: normal BMMNC + FBS + IFN- $\gamma$

FIGURE 6: POT1 mRNA expression in normal BMMNCs is reduced in the presence of SAA serum or IFN- $\gamma$.

POT1 mRNA expression in vitro as it does in SAA patients in vivo.

DNA damage initiates signal transduction pathways, known as checkpoints, which culminate in cell cycle arrest. Damaged mammalian telomeres can activate the kinases ATM and ATR. The Shelterin complex represses these two important DNA damage sentinels, preventing activation of DNA damage pathways. TRF2 is able to bind to and suppress ATM, whereas POT1 prevents activation of ATR [16]. Here, we have shown that the culture of BMMNCs in media containing SAA serum or IFN- $\gamma$ reduced expression of POT1. Therefore, we next determined the activation status of ATR in BMMNCs isolated from two normal individuals and cultured in the presence of FBS or SAA serum by measuring ATR protein levels, phosphorylation status, and activation of ATM/ATR substrates. BMMNCs cultured in FBS have very low levels of ATR, phosphorylated ATR, and phosphorylated ATM/ATR substrate; in contrast those cultured with SAA serum display a high level of these proteins (Figure 7).

We next determined the levels of ATR, phosphorylated ATR, and phosphorylated ATM/ATR substrate in normal BMMNCs cultured with FBS and TNF- $\alpha$ or IFN- $\gamma$. ATR, phosphorylated ATR, and phosphorylated ATM/ATR substrate were all found to be significantly increased in cells cultured with TNF- $\alpha$ and IFN- $\gamma$ when compared with those cultured with FBS alone (Figure 8).

\section{Discussion}

Acquired AA is prototypical of human bone marrow failure. The incidence in Western countries is two cases per million per year while in Asia this number is approximately two- to threefold higher. In China, the incidence is increased even higher with 7.4 cases per million per year [17-19]. Affected patients always have severe anemia, bleeding and infection,

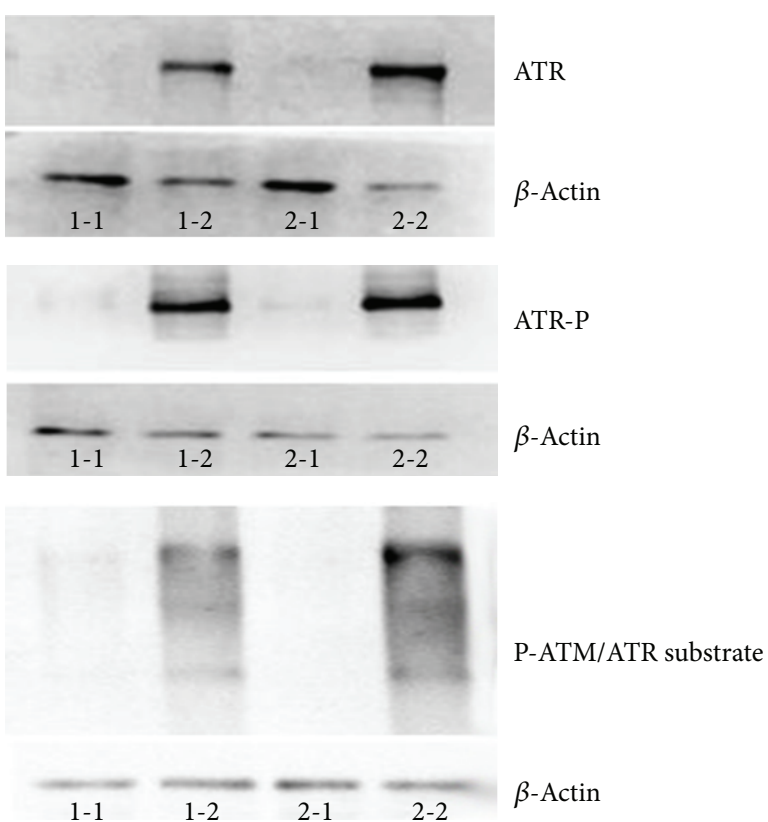

Figure 7: Culture of BMMNCs with media containing SAA serum increases activation of ATR. Legend: Samples 1-1 and 2-1: BMMNCs from two individual control patients cultured with 1640 media $+10 \%$ FBS. Samples 1-2 and 2-2: BMMNCs from the same two individual control patients cultured with 1640 media $+10 \%$ SAA serum.

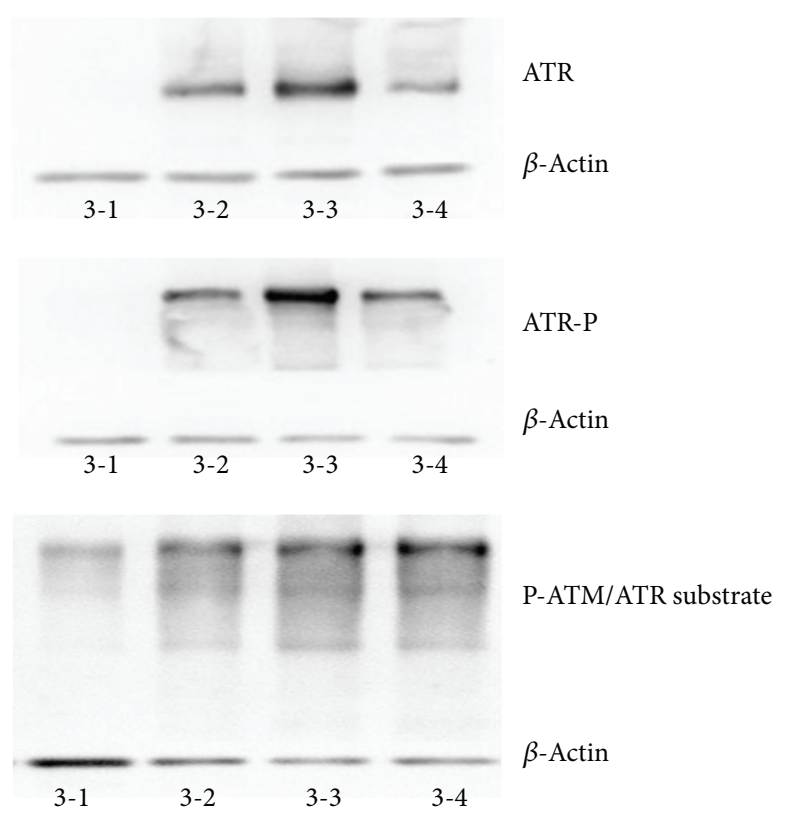

FIgURE 8: TNF- $\alpha$ and IFN- $\gamma$ increase activation of ATR in BMMNCs. Legend: Sample 3-1: BMMNCs +1640 media $+10 \%$ FBS. Sample 3-2: BMMNCs +1640 media $+10 \%$ FBS +100 U TNF- $\alpha$, Sample 3-3: BMMNCs +1640 media $+10 \%$ FBS +200 U TNF- $\alpha$, and Sample 3-4: BMMNCs +1640 media $+10 \%$ FBS +100 U IFN $-\gamma$. 


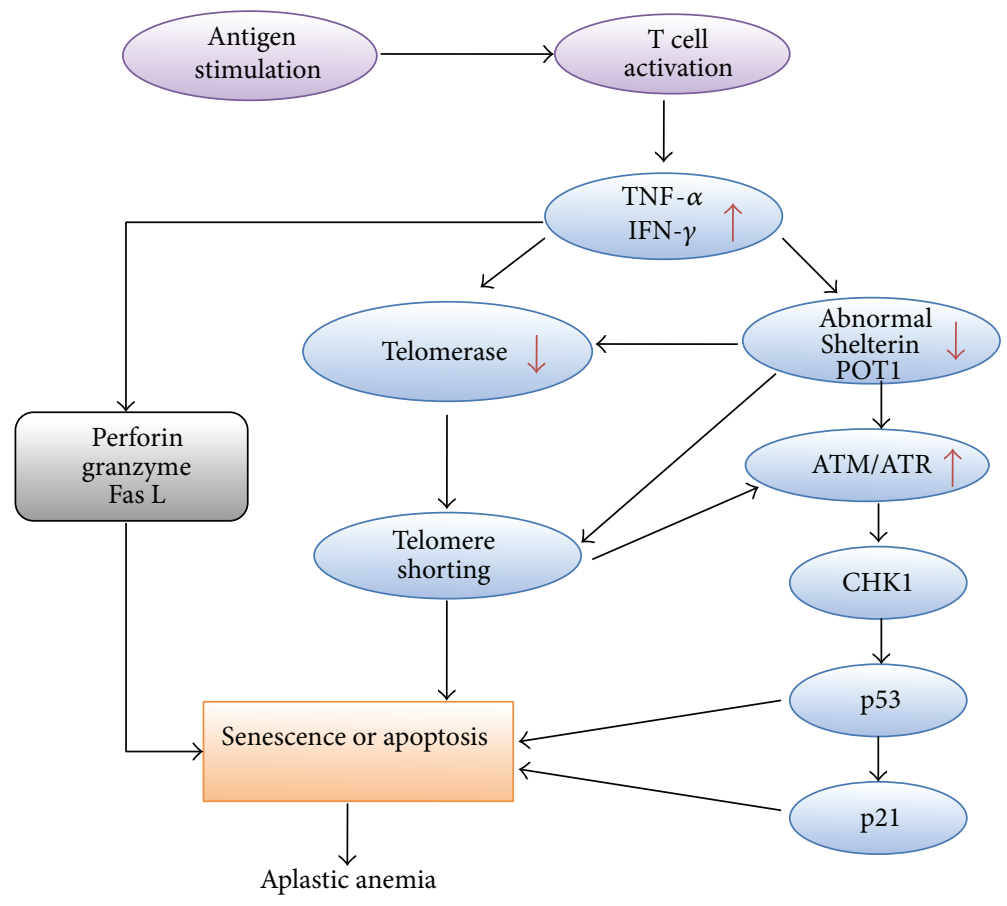

FIGURE 9: Postulated pathogenesis of aplastic anemia.

and a poor survival rate. Though immunosuppressive therapy and hematopoietic stem cell transplantation (HSCT) have well improved the treatment effect of AA, 30\% of patients do not respond favorably to treatment and may die soon after diagnosis because of heart failure, profuse hemorrhage, or overwhelming infection [20].

The precise pathophysiology of AA is unclear, with researchers predicting antigen discovery and genetic susceptibility as the two major directions for gaining a greater understanding of the disease. Other than in its response to bone marrow-suppressive agents (such as benzene and chloramphenicol), many studies have reported SAA to behave like an immune-mediated disease. Some as-yet unknown antigens can activate $\mathrm{T}$ cells to secrete marrow-suppressive cytokines (e.g., TNF- $\alpha$ and IFN- $\gamma$ ), which attack bone marrow and induce apoptosis in hematopoietic progenitor cells. These cytokines induce apoptosis through the Fas-dependent and perforin pathways of cell death [15, 21-23].

Much research has focused on the cytogenetic abnormalities of AA. Some bone marrow failure patients previously diagnosed with AA received immunosuppressive therapy but had a poor response and were later found to carry repeatable gene mutations. These patients were subsequently diagnosed with Fanconi anemia, dyskeratosis congenita, DiamondBlackfan anemia, or Shwachman-Diamond syndrome. HSCT may be chosen as a more suitable initial treatment for these diseases $[3,24,25]$. Short telomeres were identified in both the hereditary diseases above and the acquired AA. Patients with shorter telomeres (and mostly without any known telomerase mutation) had severe pancytopenia, a poor clinical response to treatment, higher possibility of relapse, an increased risk to evolve to myelodysplasia or acute myeloid leukemia, and poorer overall survival in comparison to patients with longer telomeres [26, 27]. In this study, we chose only SAA patients as subjects and found that untreated SAA patients had the shortest telomere length when compared with recovering patients and controls $(77.8 \%$ of untreated patients had a mean telomere length shorter than $5 \mathrm{~kb}$ compared with only $14.3 \%$ of recovering patients). These findings demonstrate that telomere length is regained as disease recovery progresses. In patients with $\mathrm{AA}$, helper and effector $\mathrm{T}$ cells are unbalanced; the ratio of helper/effector $\mathrm{T}$ cells is always very low, which is considered as a marker of the immune status of AA patients [28, 29]. In the present study, telomere length of PWBCs was found to correlate with $\mathrm{T}_{\mathrm{H} / \mathrm{S}}$, which means telomere length is closely related to patients' immune status. AA patients' conditions are more critical with lower hemoglobin, platelets, neutrophils, and reticulocytes. Our results indicated that the telomere length correlates with the level of HB, PLT, ANC, and Ret\%, which means the telomere length is closely related with the severity of patients' condition.

Short telomeres are found in one-third to one-half of AA patients, but mutations in genes encoding the telomerase components occur in less than $10 \%$ of cases [10]. Furthermore, mutations in Shelterin components are even rarer. Therefore, we did not detect the mutation status of genes encoding telomere-related proteins; rather we measured their expression. Telomeres are regulated by Shelterin, which plays a key role in telomere capping and telomerase regulation. POT1 has a critical role in all these activities [30]. POT1 blocks telomerase from acting by binding to the $3^{\prime}$ end of telomeric DNA. However, when telomeres become dysfunctional, their ends are sensed as double-stranded DNA 
breaks. This recognition results in the activation of DNA damage checkpoints that trigger senescence or apoptosis. POT1 inhibits the activation of the ATR kinase, a DNA damage responder that can induce both apoptosis and cell cycle arrest upon activation [31-36].

In the present study, we detected very low POT1 mRNA expression in patients with SAA. However, as POT1 is a competitive inhibitor of telomerase, telomerase in SAA patients should have a greater opportunity to elongate telomeres. Why then do SAA patients have short telomeres? Recently research demonstrates that proinflammatory cytokines including TNF- $\alpha$ and IFN- $\gamma$ inhibit telomerase activity [37-39]. Moreover, in vitro research using various cell types indicates that an accumulation of senescent cells with critically short telomere may produce proinflammatory factors, which could in turn contribute to an increased inflammatory load [4042]. SAA is a classic example of a disease that triggers $\mathrm{T}$ cells to release a great quantity of marrow-suppressive cytokines, ultimately leading to bone marrow failure. We suspect that these cytokines contribute to a poor environment, leading to both low POT1 expression and telomerase suppression. These two events occur simultaneously at the beginning of SAA and could explain why telomeres in SAA patients are shortened despite a reduction in POT1-mediated telomerase inhibition.

Once telomeres are critically short, they become dysfunctional and are recognized as double-stranded DNA breaks. This involves activation of ATM, which is normally suppressed by TRF 2 and/or activation of ATR which is normally suppressed by POT1 [43]. In SAA patients, the low expression of POT1 results in failure of ATR inhibition. Following ATR activation, cells enter either senescence or apoptosis pathways. In the third part of our study, we showed that both SAA serum and marrow-suppressive cytokines can inhibit POT1 mRNA expression and increase the expression of ATR, phosphorylated ATR, and the substrate of ATM/ATR. We therefore describe AA pathogenesis in a new figure, incorporating our novel findings and those of other recent studies (Figure 9).

\section{Conclusion}

The telomeres of SAA patients are severely shortened, with shortening correlated with the degree of illness. TNF- $\alpha$ and IFN- $\gamma$ are found at high concentrations in SAA and may be responsible for triggering senescence or apoptosis through POT1 and activation of ATM/ATR. Furthermore, SAA patients who possess short telomeres could also benefit from immunosuppressive therapy.

\section{Conflict of Interests}

All authors declare that there is no conflict of interests regarding the publication of this paper.

\section{Acknowledgments}

This work was supported by the National Natural Science Foundation of China (30971285, 30971286, 30670886, 30470749, 81370607, and 81170472), Tianjin Municipal Natural Science Foundation (08JCYBJC07800, 09JCYBJC11200, and 12JCZDJC21500), Tianjin Science and Technology support key project plan (07ZCGYSF00600), Health Industry Research and Special Projects (201202017), Tianjin Cancer Research of Major Projects (12ZCDZSY17900 and 12ZCDZSY18000), and the Tianjin Health Industry Key Projects (11KG135).

\section{References}

[1] N. Hug and J. Lingner, “Telomere length homeostasis," Chromosoma, vol. 115, no. 6, pp. 413-425, 2006.

[2] L. Kaszubowska, "Telomere shortening and ageing of the immune system," Journal of Physiology and Pharmacology, vol. 59, no. 9, pp. 169-186, 2008.

[3] N. S. Young, "Bone marrow failure and the new telomere diseases: practice and research," Hematology, vol. 17, supplement 1, pp. S18-S21, 2012.

[4] S. E. Ball, F. M. Gibson, S. Rizzo, J. A. Tooze, J. C. W. Marsh, and E. C. Gordon-Smith, "Progressive telomere shortening in aplastic anemia," Blood, vol. 91, no. 10, pp. 3582-3592, 1998.

[5] Z.-T. Xin, A. D. Beauchamp, R. T. Calado et al., "Functional characterization of natural telomerase mutations found in patients with hematologic disorders," Blood, vol. 109, no. 2, pp. 524-532, 2007.

[6] J. Takeuchi, H. Ly, H. Yamaguchi et al., "Identification and functional characterization of novel telomerase variant alleles in Japanese patients with bone-marrow failure syndromes," Blood Cells, Molecules, and Diseases, vol. 40, no. 2, pp. 185-191, 2008.

[7] H. Yamaguchi, R. T. Calado, H. Ly et al., "Mutations in TERT, the gene for telomerase reverse transcriptase, in aplastic anemia," The New England Journal of Medicine, vol. 352, no. 14, pp. 1413$1424,2005$.

[8] B. Han, B. Liu, W. Cui, X. Wang, J. lin, and Y. Zhao, "Telomerase gene mutation screening in Chinese patients with aplastic anemia," Leukemia Research, vol. 34, no. 2, pp. 258-260, 2010.

[9] S. Pigullo, E. Pavesi, I. Dianzani et al., "NOLA1 gene mutations in acquired aplastic anemia," Pediatric Blood and Cancer, vol. 52, no. 3, pp. 376-378, 2009.

[10] N. S. Young, "Bone marrow failure and the new telomere diseases: practice and research," Hematology, vol. 17, supplement 1, pp. S18-S21, 2012.

[11] A. Sfeir and T. de Lange, "Removal of shelterin reveals the telomere end-protection problem," Science, vol. 336, no. 6081, pp. 593-597, 2012.

[12] R. Diotti and D. Loayza, "Shelterin complex and associated factors at human telomeres," Nucleus, vol. 2, no. 2, pp. 119-135, 2011.

[13] T. de Lange, "Shelterin: the protein complex that shapes and safeguards human telomeres," Genes and Development, vol. 19, no. 18 , pp. 2100-2110, 2005.

[14] C. Dufour, E. Ferretti, F. Bagnasco et al., "Changes in cytokine profile pre- and post-immunosuppression in acquired aplastic anemia," Haematologica, vol. 94, no. 12, pp. 1743-1747, 2009.

[15] N. S. Young, "Pathophysiologic mechanisms in acquired aplastic anemia," Hematology, vol. 2006, no. 1, pp. 72-77, 2006. 
[16] E. L. Denchi and T. de Lange, "Protection of telomeres through independent control of ATM and ATR by TRF2 and POT1," Nature, vol. 448, no. 7157, pp. 1068-1071, 2007.

[17] D. W. Kaufman, J. P. Kelly, M. Levy, and S. Shapiro, The Drug Etiology of Agranulocytosis and Aplastic Anemia, Oxford University Press, New York, NY, USA, 1991.

[18] N. Hamerschlak, E. Maluf, R. Pasquini et al., "Incidence of aplastic anemia and agranulocytosis in Latin America-the LATIN study," Sao Paulo Medical Journal, vol. 123, no. 3, pp. 101104, 2005.

[19] S. Issaragrisil, D. W. Kaufman, T. Anderson et al., "The epidemiology of aplastic anemia in Thailand," Blood, vol. 107, no. 4, pp. 1299-1307, 2006.

[20] N. S. Young, A. Bacigalupo, and J. C. W. Marsh, "Aplastic anemia: pathophysiology and treatment," Biology of Blood and Marrow Transplantation, vol. 16, no. 1, supplement, pp. S119S125, 2010.

[21] J. Demeter, G. Messer, and H. Schrezenmeier, "Clinical relevance of the TNF-alpha promoter/enhancer polymorphism in patients with aplastic anemia," Annals of Hematology, vol. 81, no. 10, pp. 566-569, 2002.

[22] C. Dufour, M. Capasso, J. Svahn et al., "Homozygosis for (12) $\mathrm{CA}$ repeats in the first intron of the human IFN- $\gamma$ gene is significantly associated with the risk of aplastic anaemia in Caucasian population," British Journal of Haematology, vol. 126, no. 5, pp. 682-685, 2004.

[23] V. Gidvani, S. Ramkissoon, E. M. Sloand, and N. S. Young, "Cytokine gene polymorphisms in acquired bone marrow failure," American Journal of Hematology, vol. 82, no. 8, pp. 721724, 2007.

[24] K. C. Myers and S. M. Davies, "Hematopoietic stem cell transplantation for bone marrow failure syndromes in children," Biology of Blood and Marrow Transplantation, vol. 15, no. 3, pp. 279-292, 2009.

[25] R. T. Calado, “Telomeres and marrow failure," Hematology, vol. 2009, no. 1, pp. 338-343, 2009.

[26] P. Scheinberg, J. N. Cooper, E. M. Sloand, C. O. Wu, R. T. Calado, and N. S. Young, "Association of telomere length of peripheral blood leukocytes with hematopoietic relapse, malignant transformation, and survival in severe aplastic anemia," The Journal of the American Medical Association, vol. 304, no. 12, pp. 13581364, 2010.

[27] R. T. Calado, J. N. Cooper, H. M. Padilla-Nash et al., "Short telomeres result in chromosomal instability in hematopoietic cells and precede malignant evolution in human aplastic anemia," Leukemia, vol. 26, no. 4, pp. 700-707, 2012.

[28] N. S. Young, R. T. Calado, and P. Scheinberg, "Current concepts in the pathophysiology and treatment of aplastic anemia," Blood, vol. 108, no. 8, pp. 2509-2519, 2006.

[29] W. Zeng, J. P. Maciejewski, G. Chen, and N. S. Young, "Limited heterogeneity of $\mathrm{T}$ cell receptor BV usage in aplastic anemia," The Journal of Clinical Investigation, vol. 108, no. 5, pp. 765-773, 2001.

[30] P. Baumann and C. Price, "Potl and telomere maintenance," FEBS Letters, vol. 584, no. 17, pp. 3779-3784, 2010.

[31] W. Palm, D. Hockemeyer, T. Kibe, and T. de Lange, "Functional dissection of human and mouse POT1 proteins," Molecular and Cellular Biology, vol. 29, no. 2, pp. 471-482, 2009.

[32] M. F. Kendellen, K. S. Barrientos, and C. M. Counter, "POT1 association with TRF2 regulates telomere length," Molecular and Cellular Biology, vol. 29, no. 20, pp. 5611-5619, 2009.
[33] Y. Gong and T. de Lange, "A Shld1-controlled POT1a provides support for repression of ATR signaling at telomeres through RPA exclusion," Molecular Cell, vol. 40, no. 3, pp. 377-387, 2010.

[34] A. Rizzo, E. Salvati, M. Porru et al., "Stabilization of quadruplex DNA perturbs telomere replication leading to the activation of an ATR-dependent ATM signaling pathway," Nucleic Acids Research, vol. 37, no. 16, pp. 5353-5364, 2009.

[35] T. Sperka, J. Wang, and K. L. Rudolph, "DNA damage checkpoints in stem cells, ageing and cancer," Nature Reviews Molecular Cell Biology, vol. 13, no. 9, pp. 579-590, 2012.

[36] L. L. Song, L. Ponomareva, H. Shen, X. Duan, F. Alimirah, and D. Choubey, "Interferon-inducible IFI16, a negative regulator of cell growth, down-regulates expression of human telomerase reverse transcriptase (hTERT) gene," PLoS ONE, vol. 5, no. 1, Article ID e8569, 2010.

[37] L. Kaszubowska, J. J. Kaczor, L. Hak, A. Dettlaff-Pokora, M. Szarynska, and Z. Kmiec, "Sensitivity of natural killer cells to activation in the process of ageing is related to the oxidative and inflammatory status of the elderly," Journal of Physiology and Pharmacology, vol. 62, no. 1, pp. 101-109, 2011.

[38] A. O’Donovan, M. S. Pantell, E. Puterman et al., "Cumulative inflammatory load is associated with short leukocyte telomere length in the health, aging and body composition study," PLoS ONE, vol. 6, no. 5, Article ID e19687, 2011.

[39] S. T. Parish, J. E. Wu, and R. B. Effros, "Modulation of T lymphocyte replicative senescence via TNF- $\alpha$ inhibition: role of caspase-3," Journal of Immunology, vol. 182, no. 7, pp. 4237-4243, 2009.

[40] M. Akiyama, O. Yamada, T. Hideshima et al., "TNF $\alpha$ induces rapid activation and nuclear translocation of telomerase in human lymphocytes," Biochemical and Biophysical Research Communications, vol. 316, no. 2, pp. 528-532, 2004.

[41] F. Rodier, J. P. Coppe, C. K. Patil et al., "Persistent DNA damage signalling triggers senescence-associated inflammatory cytokine secretion," Nature Cell Biology, vol. 11, no. 8, pp. 973979, 2009.

[42] A. Krtolica, S. Parrinello, S. Lockett, P.-Y. Desprez, and J. Campisi, "Senescent fibroblasts promote epithelial cell growth and tumorigenesis: a link between cancer and aging," Proceedings of the National Academy of Sciences of the United States of America, vol. 98, no. 21, pp. 12072-12077, 2001.

[43] M. Thanasoula, J. M. Escandell, N. Suwaki, and M. Tarsounas, "ATM/ATR checkpoint activation downregulates CDC25C to prevent mitotic entry with uncapped telomeres," The EMBO Journal, vol. 31, no. 16, pp. 3398-3410, 2012. 


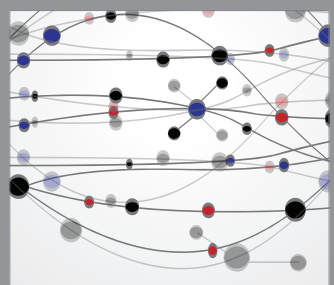

The Scientific World Journal
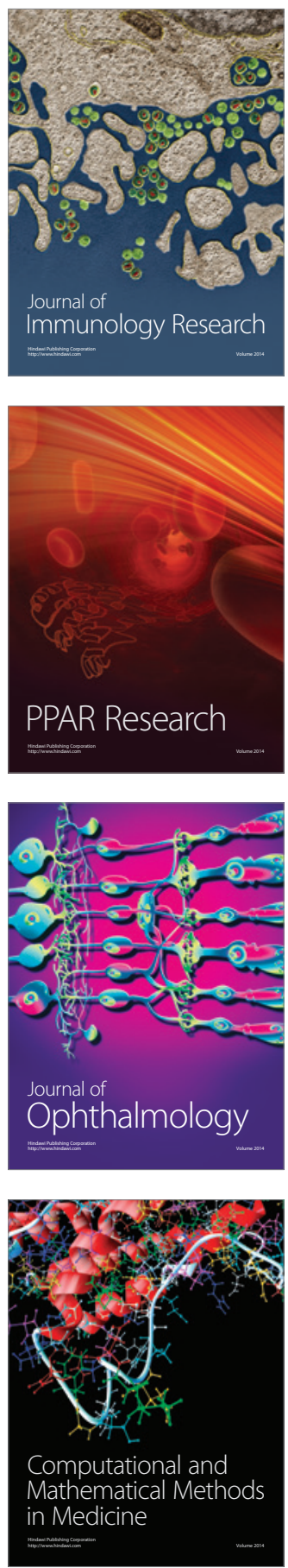

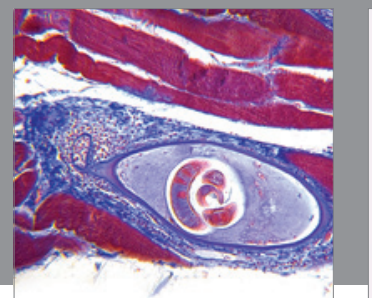

Gastroenterology

Research and Practice
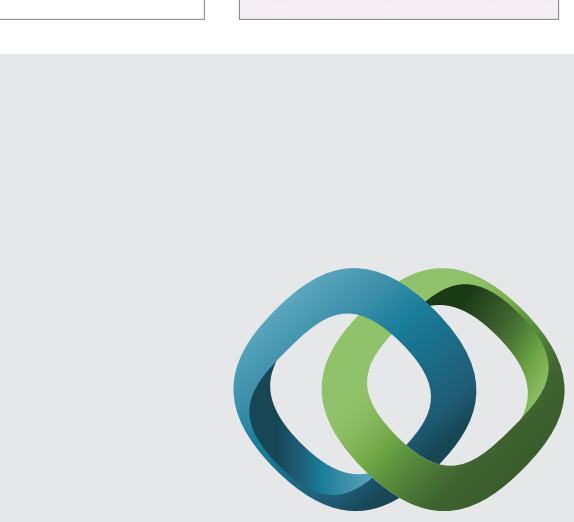

\section{Hindawi}

Submit your manuscripts at

http://www.hindawi.com
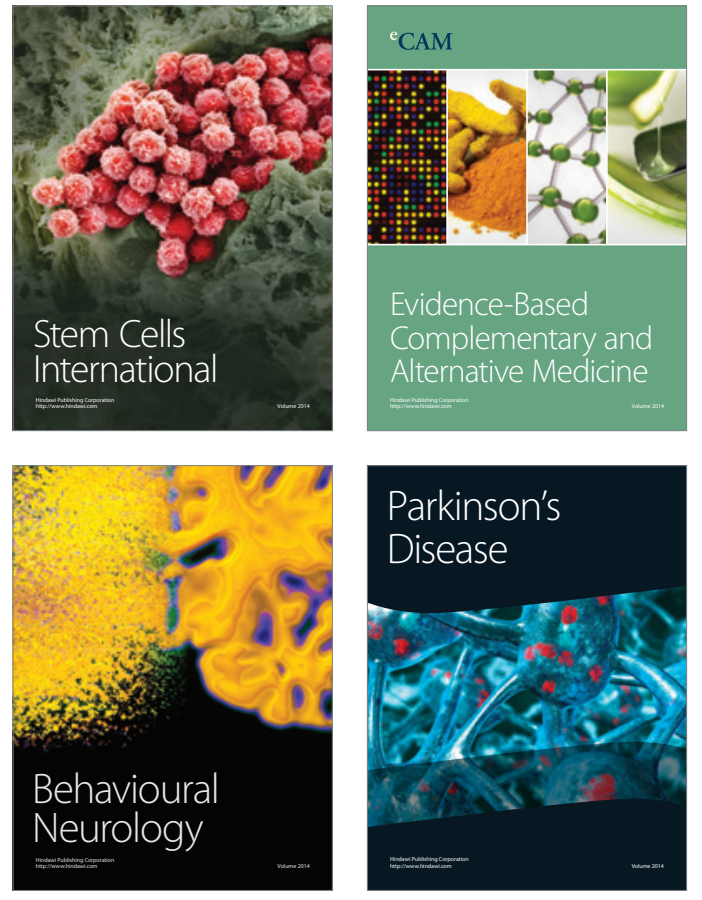
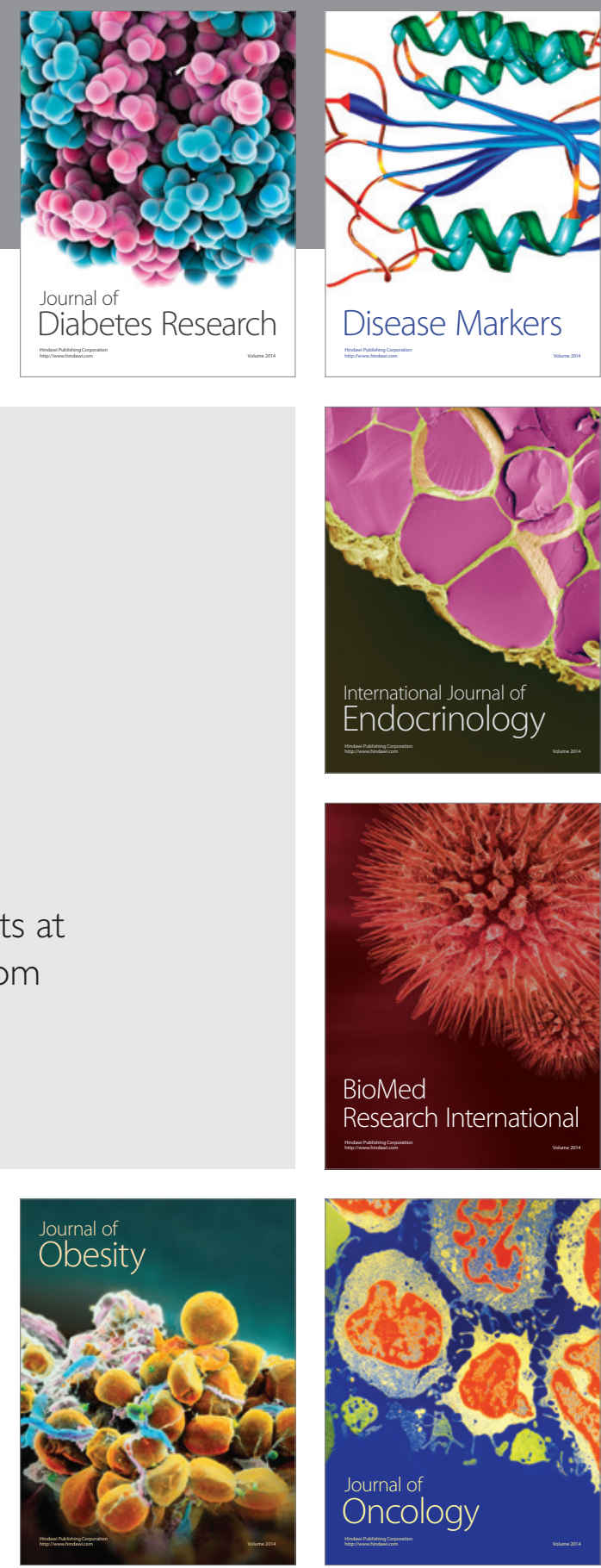

Disease Markers
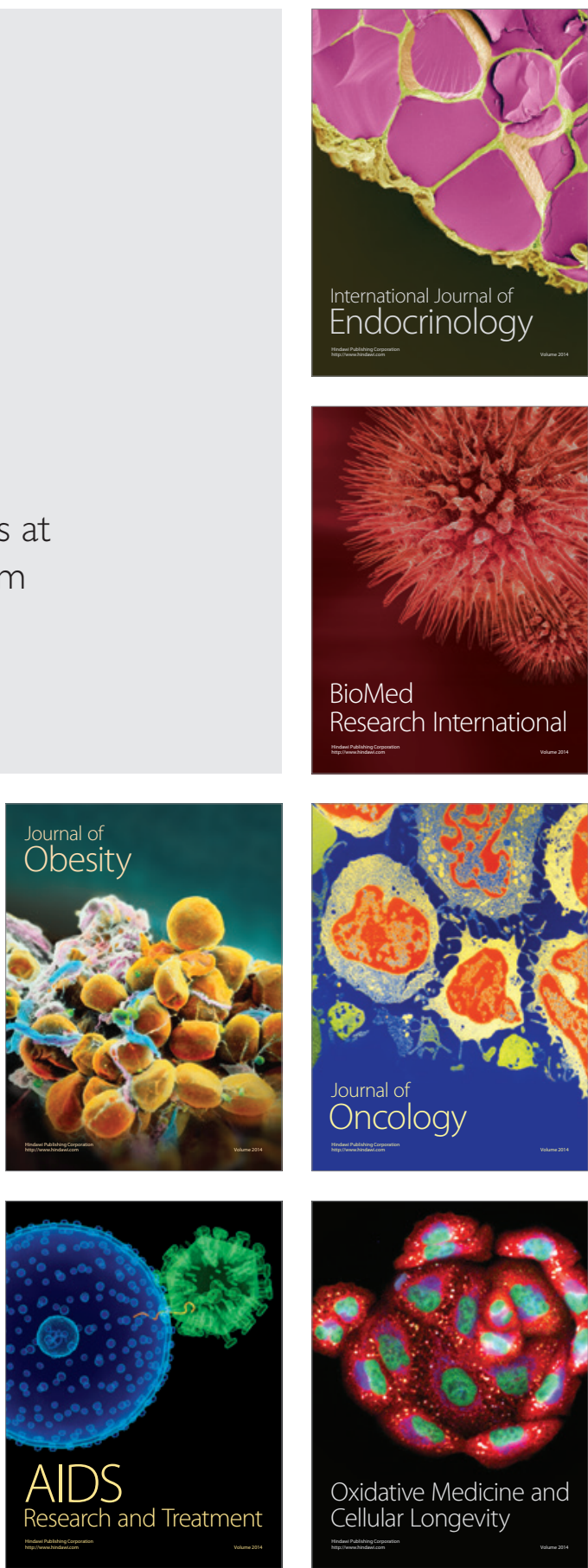